\title{
Modifikasi Pengaturan Steam Injection Valve Pada Digester Pabrik Kelapa Sawit
}

\author{
Deni Rachmat ${ }^{1} *$ Afrizal $^{2}$ \\ ${ }^{1}$ Program Studi Teknologi Pengolahan Sawit, Fakultas Vokasi, Institut Teknologi dan Sains Bandung \\ ${ }^{2}$ Asisten Proses Pabrik Kelapa Sawit, PT. Smart. Tbk \\ ${ }^{1}$ Corresponding author: deni.rachmat37@yahoo.com
}

\begin{abstract}
Abstrak. Digester adalah alat pelumat berondolan buah sawit, prosesnya dibantu oleh uap panas melalui steam injection. Steam injection berfungsi sebagai pemanas berondolan agar mudah memisahkan nut sawit dengan fibre. Salah satu persoalan yang sering terjadi pada proses pelumatan ini adalah tidak tercapainya pemerataan, waktu pemanasan standar, tingginya kebutuhan steam, dan losses minyak pada fibre. Untuk itu diperlukan suatu metode pengaturan katup Steam Injection yaitu: metode injection 1 adalah memberikan uap pada digester melalui injector tingkat 1 saja, metode 2; memberikan uap melalui injector tingkat 1 dan tingkat 2, metode 3; memberikan uap melalui injector tingkat 1 , tingkat 2, dan tingkat 3, metode injection ke empat, memberikan uap (steam) pada digester melalui injector tingkat 1 dengan bukaan valve sebasar 100\% dan tingkat 2 dengan bukaan valve sebasar 50\%. Dari hasil penelitian ini menunjukkan bahwa metode 4 yaitu tingkat 1 dengan bukaan valve $100 \%$ dan tingkat 2 dengan bukaan valve 50\% lebih efektif dalam mencapai waktu pemanasan, losses pada fibre lebih terkontrol dan memenuhi standar, waktu rata-rata pemanasan 16,12 menit, kebutuhan steam $148.5 \mathrm{~kg} /$ ton TBS, temperature rata-rata yaitu $93.3^{\circ} \mathrm{C}$, dan losses to sample $2.56 \%$ dari output screw press. Dengan diperolehnya metode yang tepat, dapat dijadikan sebagai acuan untuk pengaturan katup steam injection pada stasiun digester and press, agar dapat mengurangi losses pada proses produksi CPO.
\end{abstract}

Keywords: Digester, Steam injection, metode injeksi, losses

\section{Pendahuluan}

\subsection{Latar belakang}

Pabrik kelapa sawit (PKS) adalah tempat yang memproses atau mengolah bahan mentah Tandan Buah Segar (TBS) sawit menjadi minyak sawit mentah (Crude Palm Oil) dan minyak inti sawit (Palm Kernel Oil). Proses pengolah kelapa sawit menjadi CPO dan PKO meliputi: penerimaan Tandan Buah Segar (TBS), penyiapan TBS untuk direbus, perebusan (sterilization), penebahan (thresser), ekstraksi (digesting and pressing), pemurnian (clarification), dan pengolahan inti sawit (crushing kernel).

Digester merupakan bagian peralatan ekstraksi minyak sawit (pelumat brondolan). Digester adalah sebuah tabung yang memiliki pisau pengaduk bertingkat yang dikopelkan pada sebuah shaft. Pisau ini berfungsi untuk mengaduk dan menghomogenkan masa brondolan sehingga akan memudahkan proses pengekstrasian di mesin press. Digester dalam prosesnya membutuhkan injeksi uap (steam injection) dari boiler yang berfungsi sebagai proses pemanasan dan pelunakan daging brondolan saat brondolan dicacah. Dengan adanya injeksi uap ini waktu yang dibutuhkan untuk pelunakan brondolan akan lebih cepat, mempermudah lepasnya sel minyak dari pericarp dan mudah terpisahnya pericarp dari nut sawit. Digester memiliki peralatan katup pengatur injector guna mempertahankan temperature pada nilai $90^{\circ} \mathrm{C}-95^{\circ} \mathrm{C}$ dan tersebar merata dalam tabung digester [2].

Steam injektor pada satu digester dapat terdiri dari 1 tingkat, 2 tingkat dan 3 tingkat, setiap tingkat tentunya harus memiliki parameter yang sama, yaitu menghasilkan minyak dengan kadar lemak bebas yang sedikit, rendemen yang tinggi dan waktu pelunakan cepat. Selain hal tersebut di atas, masing-masing tingkat 
tentunya akan memiliki karakteristik digester yang berbeda, dan masing-masing tingkat memiliki keuntungan dan kerugian yang berbeda.

Dengan demikian penelitian ini fokus pada pengaturan steam injection di digester statsiun press dengan memperhatikan parameter-parameter keberhasilan proses pengolahan sawit yaitu kadar lemak bebas (FFA) yang sedikit dari hasil proses digester, rendemen digester, loss fiber di bawah standar 4.6\% [2] dan waktu pemanasan pelunakan berondolan dalam waktu yang singkat.

\subsection{Batasan masalah}

Masalah penelitian ini dibatasi pada salah satu faktor kinerja digester yaitu temperature, menggunakan 4 metode, waktu pemanasan menuju temperatur SOP $90-95^{\circ} \mathrm{C}$ [2] dan pengamatan real time sampai pemanasan merata.

\section{Metodologi Penelitian}

\subsection{Diagram alir}

Penelitian ini adalah modifikasi pengaturan steam injection pada Digester Pabrik Kelapa Sawit, Gambar 41 menunjukkan diagram alir penelitian.

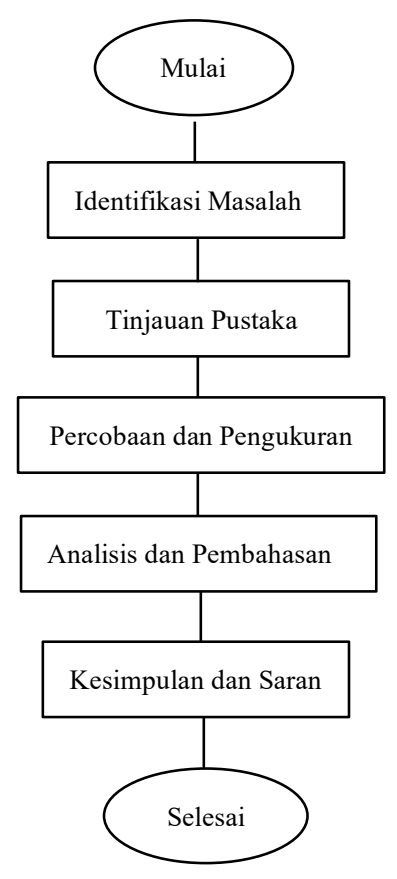

Gambar 41. Diagram alir penelitian

Langkah awal yang dilakukan pada penelitian ini adalah mengidentifikasi masalah, selanjutnya melakukan tinjauan pustaka, tinjauan pustaka ini dilakukan untuk menentukan landasan teori yang mendukung pada penelitian ini, kemudian melakukan percobaan dan pengukuran. Hasil dari percobaan dan pengukuran ini dianalisis dan dibahas dengan didukung oleh teori-teori pada langkah sebelumnya. Setelah melakukan analisis dan pembahasan kemudian menarik kesimpulan dan saran.

\subsection{Prosedur Percobaan dan Pengukuran}

Berikut Gambar 42 di bawah ini menunjukkan diagram satu garis prosedur percobaan dan pengukuran. 


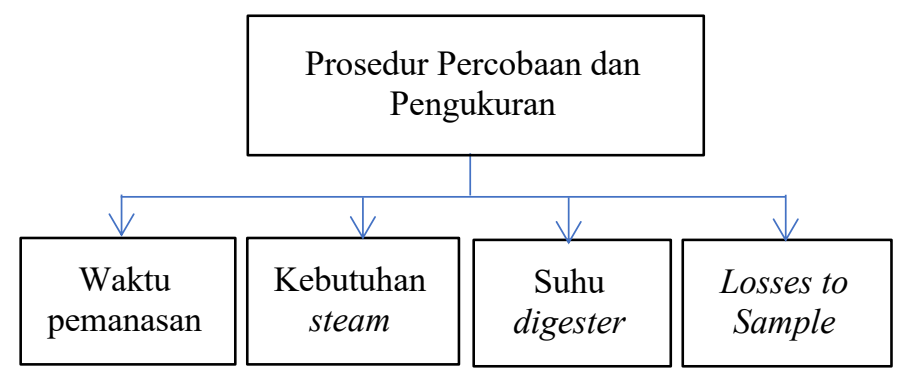

Gambar 42. Diagram satu garis prosedur percobaan dan pengukuran

Keterangan diagram sebagai berikut:

1. Waktu Pemanasan: Buka valve steam injector, ukur waktu pemanasan, catat data waktu pemanasan, ulangi pengukuran.

2. Kebutuhan steam: Ukur diameter pipa masuk vessel BPV dan pipa keluar BPV, gunakan persamaan 1.2 sampai dengan 1.5 , catat hasil perhitungan.

3. Suhu digester: Ukur temperatur dibeberapa titik pengukuran (titik atas, bawah dan tengah) pada digester, ulangi pengukuran.

4. Losses to sample: Ambil sampel dari mesin press, cacah sample, timbang sample basah, masukan sample ke dalam oven microwave, timbang sample kering, soxhlet sample, masukan bottom flask yang berisi minyak hasil soxlet sample, lakukan perhitungan menggunakan persamaan 1.1.

\subsection{Alat dan Bahan}

Peralatan dan bahan yang digunakan dalam penelitan ini adalah sebagai berikut:

a. Tabung digester Pabrik Kelapa Sawit yang sudah terisi cake digunakan sebagai tempat percobaan penelitian.

b. Thermolaser digunakan untuk mengukur suhu dibeberapa titik dan sampel dalam tabung digester.

c. Stopwatch digunakan untuk mengukur waktu kenaikan suhu pada beberapa titik dan sampel.

d. Steam flow meter sebagai alat indikator laju aliran steam dari boiler (sebagai pengukur kebutuhan steam pada digester).

e. Steam Chart digunakan untuk mengukur debit steam boiler.

f. Sample fiber dan peralatan laboratorium (petri dish, microwave oven, thimble dan soxhlet, bottom flask, analytical balance) untuk mengukur sampel minyak yang ada di fiber (digunakan untuk mengukur losses minyak).

\section{Pembahasan}

\subsection{Menentukan identifikasi permasalahan}

Untuk identifikasi masasalah digunakan metode diagram Ishikawa, dari diagram tersebut diperoleh persoalan yaitu tidak tercapainya temperature steam injection pada digester, hal ini disebabkan oleh metodenya yaitu metode pengaturan steam injection, yang mana pada metode sebelumnya adalah membiarkan steam injection pada digester tanpa pengendalian.

\subsection{Modifikasi Pengaturan Steam Injection pada digester}

Modifikasi pengaturan didasarkan pada kombinasi kemungkinan bukaan katup yang dapat dipilih, dengan pemilihan metode kandidat awal berpedoman pada maksimum kebutuhan uap dan minimum bukaan katup (100\%). Dari hasil pemilihan awal kandidat terpilih ada 4 metode yaitu:

1. Metode 1, dengan mengatur katup tingkat 1 saja dengan bukaan katup $100 \%$, diperoleh data sebagai berikut:

a. Waktu rata-rata yang dibutuhkan untuk mencapai temperature $90-95^{\circ} \mathrm{C}, 30.09$ menit.

b. Kebutuhan Uap $99 \mathrm{~kg} / \mathrm{ton}$ TBS.

c. Temperature rata-rata titik atas digester $89.4^{\circ} \mathrm{C}$, titik tengah $90.9^{\circ} \mathrm{C}$, dan titik bawah $91.6^{\circ} \mathrm{C}$.

d. Rata-rata losses $3.94 \%$ (di bawah standar 4.6\%) [2].

2. Metode 2, dengan mengatur katup tingkat 1 dan tingkat 2 dengan bukaan katup $100 \%$ diperoleh data sebagai berikut:

a. Waktu rata-rata yang dibutuhkan untuk mencapai temperature $90-95^{\circ} \mathrm{C}, 10.15$ menit. 
b. Kebutuhan Uap $189 \mathrm{~kg} /$ ton TBS.

c. Temperature rata-rata titik atas digester $91.8^{\circ} \mathrm{C}$, titik tengah $92.5^{\circ} \mathrm{C}$, dan titik bawah $92.8^{\circ} \mathrm{C}$.

d. Rata-rata losses $2.81 \%$ (di bawah standar 4.6\%) [2].

3. Metode 3, dengan mengatur bukaan katup tingkat 1, tingkat 2 dan tingkat 3 dengan bukaan katup $100 \%$ diperoleh data sebagai berikut:

a. Waktu rata-rata yang dibutuhkan untuk mencapai temperature $90-95^{\circ} \mathrm{C}, 8.25$ menit.

b. Kebutuhan Uap $297 \mathrm{~kg} /$ ton TBS.

c. Temperature rata-rata titik atas digester $92.9^{\circ} \mathrm{C}$, titik tengah $93.5^{\circ} \mathrm{C}$, dan titik bawah $93.2^{\circ} \mathrm{C}$.

d. Rata-rata losses cukup besar (terjadi penumpahan cake dan minyak pada input digester).

4. Metode 4, dengan mengatur bukaan katup tingkat $1=100 \%$ dan tingkat $2=50 \%$.

a. Waktu rata-rata yang dibutuhkan untuk mencapai temperature $90-95^{\circ} \mathrm{C}, 16.12$ menit.

b. Kebutuhan Uap $148.5 \mathrm{~kg} /$ ton TBS,

c. Temperature rata-rata titik atas digester $93.3^{\circ} \mathrm{C}$, titik tengah $93.3^{\circ} \mathrm{C}$, dan titik bawah $93.1^{\circ} \mathrm{C}$.

d. Rata-rata losses $2.56 \%$ (di bawah standar 4.6\%) [2].

\section{Kesimpulan dan Saran}

Dari hasil penelitian ini diperoleh kesimpulan bahwa metode steam injection yang dipilih adalah metode 4 yaitu bukaan katup steam injeksi tingkat 1 sama dengan 100\% dan tingkat 2 sama dengan 50\%, dengan waktu rata-rata pemanasan 16.12 menit, kebutuhan steam sebanyak $148.5 \mathrm{~kg} /$ ton TBS, temperature ratarata $93.3^{\circ} \mathrm{C}$ dan losses to sample terendah $2.56 \%$ dari standar $4.6 \%$.

Saran yang dapat disampaikan kedepan yaitu metode pengaturan steam injection ini dapat dikendalikan secara otomatis menggunakan peralatan kontrol, sehingga steam injection pada digester dapat dikendalikan secara tepat baik untuk dari sisi temperature, waktu pemanasannya dan volume uap masuk digester.

\section{Daftar Pustaka}

[1] Palm Oil Mill Over View, Sinarmas Agribisnis and Food, Jakarta 2005

[2] Standar Operation Prosedur (SOP), pengolahan pabrik kelapa sawit PT. Smart. Tbk

[3] Human Resources Learning Centre, BMDPE-Mill Proses, Jakarta PT.Smart. Tbk

[4] Afrizal, "Kajian Modifikasi Steam Injection pada Digester", Kota Deltamas 2017

[5] Jefri Pratama, "Kajian Pengaruh Penambahan Plat Strip pada Lori terhadap Oil Losses in Empty Bunch", Kota Deltamas 2015.

[6] Agus Rahman, “ Laporan Kerja Praktik PT. Smart. Tbk Batu Ampar Mill”, 2016 